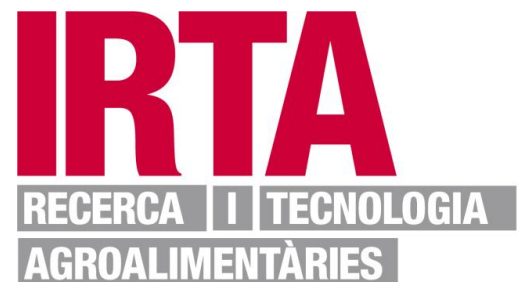

This is a post-peer-review, pre-copyedit version of an article published in Irrigation Science. The final authenticated version is available online at: https://doi.org/10.1007/s00271-018-0586-8

Document downloaded from:

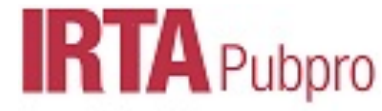

Open digital archive 


\title{
Utility of the Two-Source Energy Balance (TSEB) model in vine and interrow flux partitioning over the growing season
}

\author{
W.P. Kustas ${ }^{1}$, J.G. Alfieri ${ }^{1}$, H. Nieto ${ }^{2}$, T.G. Wilson ${ }^{1}$, F. Gao ${ }^{1}$, M.C Anderson ${ }^{1}$ \\ ${ }^{1}$ USDA-ARS, Hydrology and Remote Sensing Laboratory, Beltsville, MD \\ ${ }^{2}$ IRTA-Research \& Technology Food \& Agriculture, Lleida, Spain
}

\section{Abstract}

For monitoring water use in vineyards, it becomes important to evaluate the evapotranspiration (ET) contributions from the two distinct management zones: the vines and the interrow. Often the interrow is not completely bare soil but contains a cover crop that is senescent during the main growing season (nominally May-August), which in Central California is also the dry season. Drip irrigation systems running during the growing season supply water to the vine plant and re-wet some of the surrounding bare soil. However, most of the interrow cover crop is dry stubble by the end of May. This paper analyzes the utility of the thermal-based Two-Source Energy Balance (TSEB) model for estimating daytime ET using tower-based land surface temperature measurements over two Pinot Noir (Vitis vinifera) vineyards at different levels of maturity in the Central Valley of California near Lodi, CA. The data were collected as part of the Grape Remote sensing Profile and Evapotranspiration eXperiment (GRAPEX). Local eddy covariance (EC) flux tower measurements are used to evaluate the performance of the TSEB model output of the fluxes and the capability of partitioning the vine and cover crop transpiration (T) from the total ET or T/ET ratio. The results for the 2014-2016 growing seasons indicate that TSEB output of the energy balance components and ET, particularly, over the daytime period yield relative differences with flux tower measurements of less than $15 \%$. However, the TSEB model in comparison with flux partitioning method overestimates T/ET during the winter and spring through bud break, but then underestimates during the growing season. A major factor that appears to affect this temporal behavior in T/ET is the daily LAI used as input to TSEB derived from a remote sensing product.

Keywords vineyards, remote sensing, two source energy balance model, eddy covariance, evapotranspiration, evaporation, transpiration, land surface temperature 


\section{Introduction}

The typical architecture of wine-grape vineyards in California is characterized by widely spaced rows $(\sim 3 \mathrm{~m})$ and tall plants $(\sim 2 \mathrm{~m})$ with most of the biomass concentrated in the upper one-third to one-half of the plant. This wide row spacing and canopy architecture facilitates sunlight interception, air flow, and field operations. It also results in two distinct management zones: the vines and the interrow. Often, the treatment of these two management zones is further complicated by a cover crop grown in the interrow. A remote sensing-based land surface model that captures the micro and macro-scale exchanges between the vine, interrow and atmospheric boundary layer is needed to operationally monitor vineyard water use and both vine and interrow plant stress. The Two-Source Energy Balance (TSEB) formulation addresses the key factors affecting the convective and radiative exchange within the soil/substrate-plant canopy45 atmosphere system.

As water supplies for agricultural production become more restricted due to overuse and drought, particularly in arid regions, there is a concerted effort to improve irrigation methods to reduce the amount of water lost through soil evaporation (E) versus transpiration $(\mathrm{T})$ since for any contribution from an agronomic point of view. While a number of measurement techniques have been developed to estimate T and E (Kool et al., 2014), they are very difficult to extrapolate from the local patch scale to field scale and certainly to landscape and regional scales. This study presents an application of the TSEB model for estimating evapotranspiration (ET) that explicitly partitions ET to T and E using land surface temperature (LST), which is also available from satellites, giving it a regional scale application.

In this paper, TSEB is applied using local tower LST observations representing conditions surrounding the eddy covariance flux tower. Both the total ET and the partitioned fluxes from vine and interrow systems estimated by TSEB are compared to eddy covariance ET. Additionally, for 2014 and 2015 growing seasons, the T/ET ratio is estimated using the correlation-based flux partitioning method with the high frequency eddy covariance data (Scanlon and Sahu, 2008; Scanlon and Kustas, 2010; 2012). Comparisons in partitioning between $\mathrm{E}$ and $\mathrm{T}$ on monthly timescales will be used since there were frequent periods lacking convergence with the correlation-based flux partitioning method, but on a monthly time scale there were enough values to compare the partitioning to significant changes in vine and interrow cover crop phenology.

\section{Approach}

The TSEB model has undergone several modifications since it was first presented by Norman et al. (1995). Changes include refinements to the algorithm estimating soil aerodynamic resistance and shortwave and longwave transmittance through the canopy and addition of the 
71 Priestley-Taylor formulation for canopy transpiration (Kustas and Norman, 1999). Further

72 improvements have been made incorporating rigorous treatment of radiation modeling for

73 strongly clumped row crops and accounting for shading effects on soil heat flux (Colaizzi et al.

74 2012a; 2016a; 2016b) as well as alternative formulations for computing the canopy transpiration

75 which include Penman-Monteith (PM) or light-use efficiency (LUE) parameterizations (see

76 Colaizzi et al., 2012b; 2014; 2016c; Anderson et al., 2008).

77 Further refinements have been recently made to the within-canopy wind profile (Nieto et al., 78 this issue: a) to address the significant vertical variation in vine biomass which is often

79 concentrated in the upper half of the canopy with a secondary cover-crop biomass in the

80 interrow. This adjustment involved creating generic canopy profile distributions for four major

81 seasonal/phenological stages. The first period is just before vine bud break when vines-shoots are 82 already pruned and there is an actively growing cover crop (March-April). The second period 83 starts with vine bud break during the spring (April-May); at this time vine development is in the 84 upper $\sim 1 / 3$ of the canopy between the first cordon where the vine shoots originate $(\sim 1.45 \mathrm{~m}$ 85 above ground level (AGL)) and second cordon ( 1.90 m AGL) on the vine trellis system. The 86 cover crop remains vigorous until it is mowed at the end of this period. In the third period, which 87 exists over an extended growing season and past harvest as the vines go through senescence 88 (June-November), the foliage distribution is concentrated approximately midway between the 89 ground and top of the vine canopy with no photosynthetic grass layer. Finally, a fourth 90 distribution covers the period after vine leaf-off with standing vine shoots and a re-emerging 91 cover crop (December-February).

92 Additionally, a simplified method to derive the clumping index for radiation modeling in 93 vineyards was derived following the geometric model from Colaizzi et al. (2012a). A rectangular 94 canopy shape, which simplifies the trigonometric calculations, replaces the elliptical hedgerow 95 assumption in the original model. Results with this new modeling approach show similar 96 accuracy to detailed three-dimensional radiation modeling schemes (Parry et al., this issue). A 97 full description of the model formulations, modified and applied to the vineyard site using tower98 based thermal measurements and aerial imagery, is provided in Nieto et al. (this issue: a \& b). A 99 description of the key TSEB model algorithms is provided in the Appendix and also in Nieto et 100 al. (this issue; a)

\section{Materials and methods}

The meteorological measurements were obtained from the flux towers located in the north (site 1) and south (site 2) vineyards (see Figure 1). The vineyards are Pinot Noir (Vitis vinifera) variety with the north vineyard planted in 2009 and the south vineyard planted in 2011. Details of the flux tower measurements and processing are described by Alfieri et al. (this issue). In both 2014 and 2015, there was nearly a continuous set of high frequency eddy covariance data 
available that allowed for estimates of the monthly T/ET estimates using the correlation-based flux partitioning eddy covariance (EC) method. Unfortunately, in 2016 there was a loss of the high frequency data during the main growing season so it could not be used in this analysis. The input forcing data used in this study include 15-minute wind speed measured at $5 \mathrm{~m}$ AGL from a three-dimensional sonic anemometer (CSAT3, Campbell Scientific, Logan Utah), air temperature from a Gill shielded temperature/humidity probe (HMP45C, Vaisala Helsinki, Finland), and incoming and outgoing shortwave and longwave radiation using a four-component net radiometer (CNR-1, Kipp and Zonen, Delft, Netherlands) mounted at $6 \mathrm{~m}$ AGL. The upwelling longwave radiation was used to compute a composite hemispherical LST (Norman 117 and Becker, 1995).

The measurements were collected in two vineyards located approximately 32 $\mathrm{km}(\sim 20 \mathrm{mi})$ northeast of Lodi, CA $\left(38.29^{\circ} \mathrm{N}, 121.12^{\circ} \mathrm{W}\right)$.

East-WestRows spaced $\sim 3.3 \mathrm{~m}$ (11 ft). Vines spaced $\sim 1.5 \mathrm{~m}(5 \mathrm{ft}$ ).
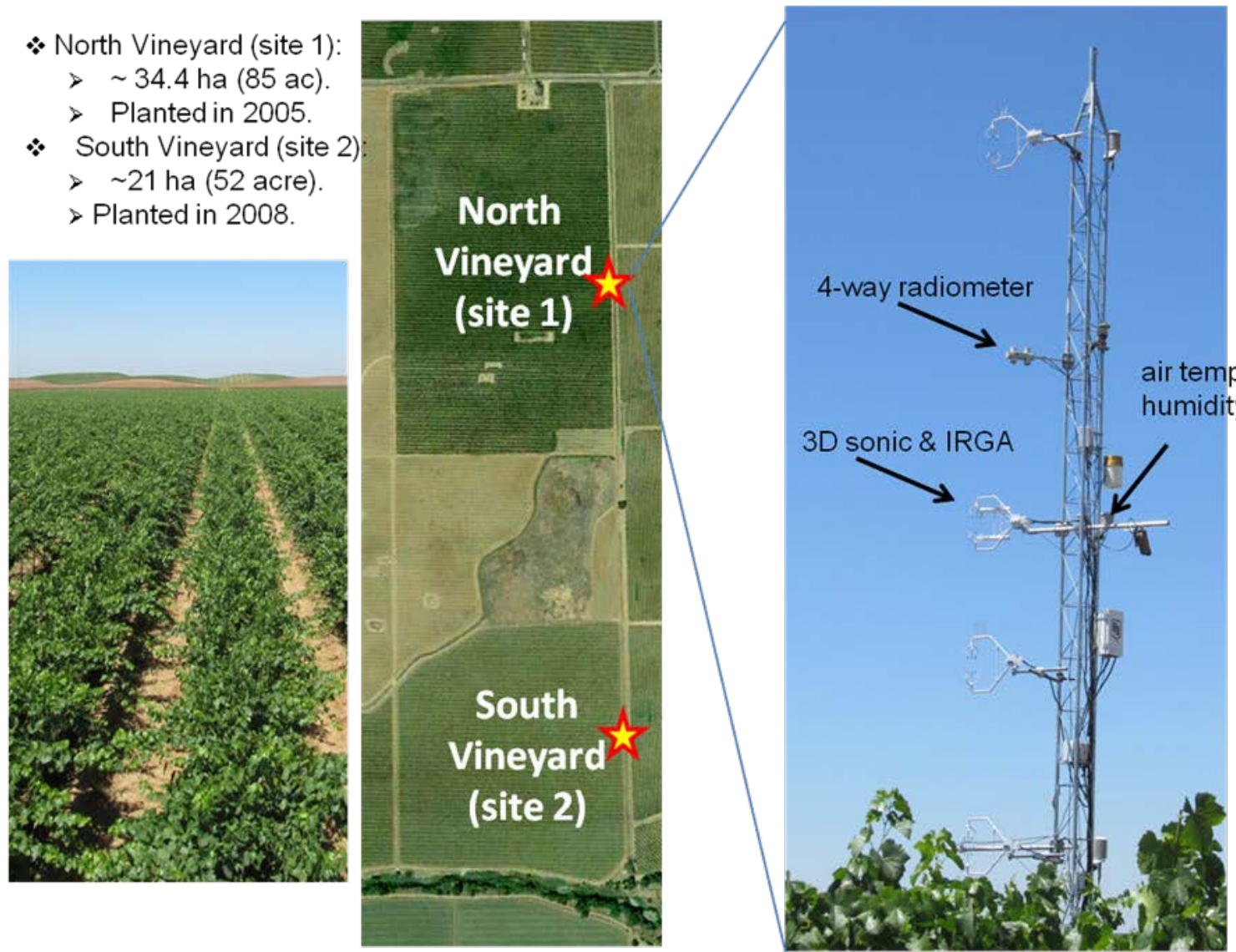

Figure 1. Description of study site and tower sensors used for running TSEB 
Other key inputs of canopy height, aerodynamic surface roughness, and leaf area index (LAI) were obtained from ground measurements during intensive observation periods (IOPs) which occurred during different key vine and cover crop phenological stages, namely April/May, June/July and August/September. However, the ground measurements required interpolation to daily values to run TSEB with the meteorological and LST inputs. For LAI, a machine learning approach (Gao et al., 2012) was applied to generate daily LAI maps at $30 \mathrm{~m}$ resolution over the GRAPEX field sites using Landsat surface reflectance and the MODIS LAI products. Agreement between the remotely sensed retrieved LAI and ground LAI measurements from 2013 through 2016 yielded an average difference around 25\% (Sun et al., 2017). Daily canopy height was interpolated based on its relationship to LAI from Nieto et al. (this issue; a), and the aerodynamic roughness parameters were obtained from wind direction relative to vine row orientation (eastwest rows) and their relationship to LAI derived by Alfieri et al. (this issue). Daily green vegetated fraction $\left(f_{G}\right)$ used in the Priestley-Taylor formulation for canopy transpiration (see Nieto et al., this issue; a) was estimated based on the day of year when senescence begins $\left(D O Y_{S}\right)$, which was observed from daily phenocam photos. $f_{G}$ is 1 prior to $D O Y_{S}$, then from $D O Y_{S}$ onward $f_{G}$ follows a linearly decreasing function of LAI:

$$
f_{G}\left(D O Y>D O Y_{S}\right)=\left[\operatorname{LAI}(D O Y)-L A I_{\text {min }}\right] /\left[L A I\left(D O Y_{S}\right)-L A I_{\text {min }}\right]
$$

Here, $D O Y$ is day of year and $L A I_{\min }$ is the estimated minimum annual value of LAI.

The value of the hemispherical LST $\left(T_{R H}\right)$ can be computed based on the following expression:

$T_{R H}=\left(\left[R_{L \uparrow}-\left(1-\varepsilon_{H}\right) R_{L \downarrow}+R_{L a t m}\right] / \sigma \varepsilon_{H}\right)^{1 / 4}$

where $R_{L \uparrow}$ is the upwelling longwave radiation measurement, $R_{L \downarrow}$ is the downwelling longwave radiation, $R_{\text {Latm }}$ is the atmospheric longwave contribution from ground to sensor height, $\sigma$ is Stephan-Boltzmann constant and $\varepsilon_{H}$ is the hemispherical emissivity estimated from weighting the fractional vegetation cover estimates $\left(f_{C}\right)$ with assumed emissivity of the canopy $(0.99)$ and soil/cover crop (0.94) as follows $\varepsilon_{H}=0.99\left(f_{C}\right)+0.94\left(1-f_{C}\right)$. Given the relatively small path length of the longwave sensor from the ground, it was assumed $R_{L a t m} \sim 0$.

\section{Results}

For the years 2014-2016, the 15-minute average meteorological and LST forcing data were used in TSEB along with daily LAI and aerodynamic roughness parameters to compute surface energy fluxes over the daytime period, which is defined when net radiation is greater than $100 \mathrm{~W}$ 
$\mathrm{m}^{-2}$. The TSEB output for years 2014-2016 were computed. Since the focus is on ET and its partitioning between the vine canopy and the interrow, the model and measured results are compared using daytime ET and, when available, T/ET estimates using the correlation-based method with high frequency eddy covariance data. As noted above, comparison of TSEB model

185 estimates of T/ET with the correlation-based method was conducted on a monthly time scale and 186 could only be carried out for years 2014 and 2015.
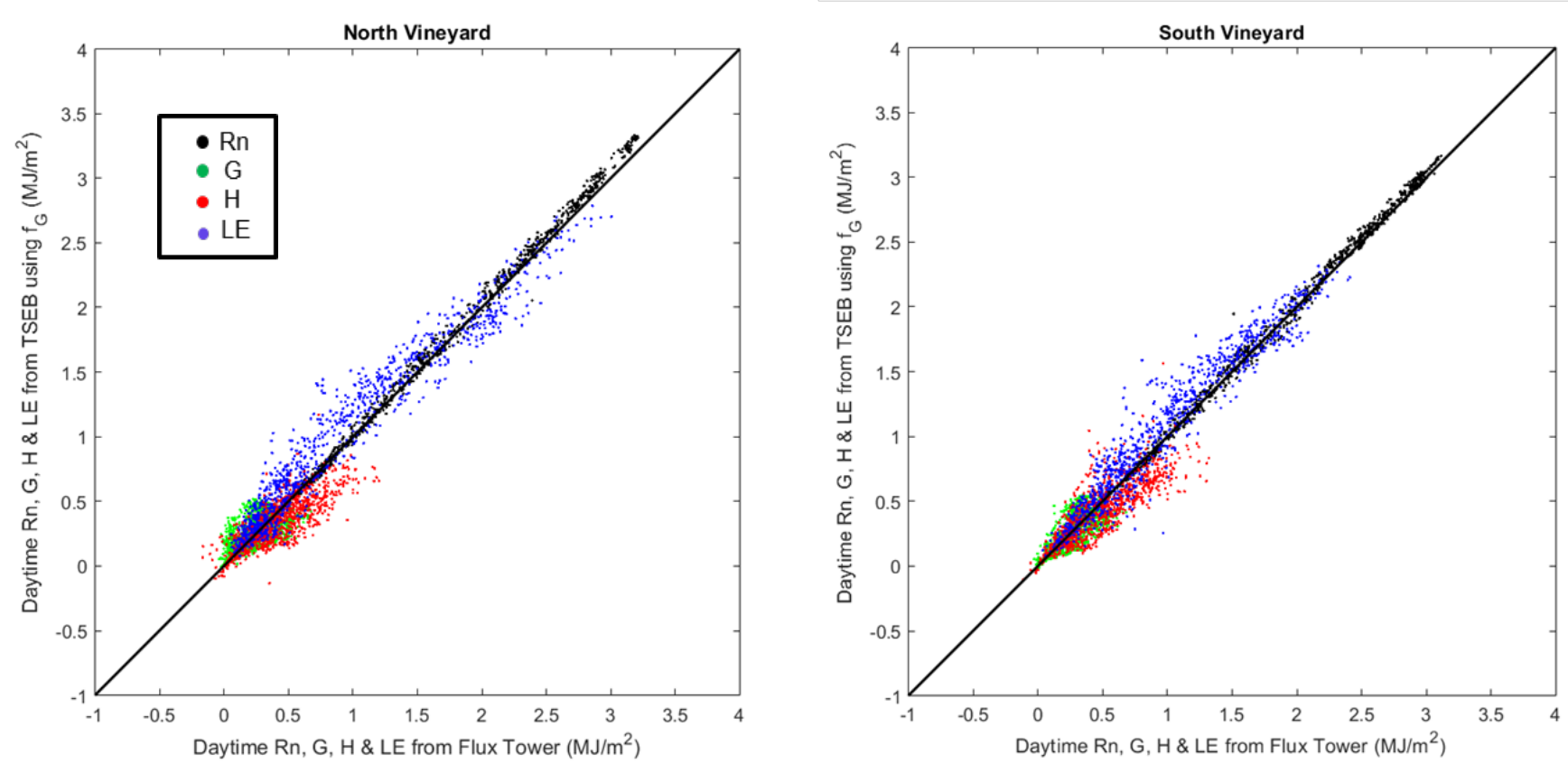

Figure 2. Comparison of daytime net radiation $(\mathrm{Rn})$, soil heat flux $(\mathrm{G})$, sensible heat flux $(\mathrm{H})$ and latent heat flux (LE) computed from hourly flux tower measurements from 2014-2016 for the north and south vineyards versus estimated from TSEB using $f_{G}$ estimated from Eq. (1).

The difference statistics with observed daytime ET (mm) and daytime H (MJ) for the different foliage distributions are listed in Table 1. Since the leaf-off and bud break statistical results were virtually the same, those two stages are combined in the table. The mean absolute percentage difference (MAPD) value, as defined in Table 1, was used as the key performance metric since it factors in the relative magnitude of the observed flux to the model-measurement difference. For the north vineyard, the performance of TSEB in LE is notably better over the 
219 growing season through senescence for all years while the spring or the leaf-off through bud break periods produced the greatest errors. However, for $\mathrm{H}$ difference statistics, the tendency was to have the largest errors during the growing season when ET is largest and $\mathrm{H}$ tends to be relatively small due to frequent irrigations combined with advection of heat from the surrounding mostly dry, arid region. For the south vineyard, MAPD values for LE estimation tended to be largest for leaf-off and bud-break periods, which was also the case for $\mathrm{H}$ (except in 2016). Hence for the south vineyard it appears that the largest relative errors in ET have correspondingly the greatest relative errors in $\mathrm{H}$, but this is not the case the north vineyard.

Table 1. Difference statistics between TSEB and measured daily daytime LE or ET (mm) and H $\left(\mathrm{MJ} / \mathrm{m}^{2}\right)$ for the different vine and cover crop phenological conditions

\begin{tabular}{|c|c|c|c|c|c|c|c|c|c|c|c|c|}
\hline & 2014 & 2014 & 2014 & 2015 & 2015 & 2015 & 2016 & 2016 & 2016 & 2014 & 2015 & 2016 \\
\hline & December-March & April-May & June-November & December-March & April-May & June-November & December-March & April-May & June-November & Full Year & Full Year & Full Year \\
\hline & $\begin{array}{l}\text { leaf-off \& bud } \\
\text { break }\end{array}$ & Spring & $\begin{array}{c}\text { Growing Season \& } \\
\text { Senescense }\end{array}$ & $\begin{array}{l}\text { leaf-off \& bud } \\
\text { break }\end{array}$ & Spring & $\begin{array}{c}\text { Growing Season \& } \\
\text { Senescense }\end{array}$ & $\begin{array}{l}\text { leaf-off \& bud } \\
\text { break }\end{array}$ & Spring & $\begin{array}{c}\text { Growing Season \& } \\
\text { Senescense }\end{array}$ & & & \\
\hline \multicolumn{13}{|c|}{ Difference Statistics } \\
\hline \multicolumn{13}{|c|}{ North Vineyard } \\
\hline \multicolumn{13}{|c|}{ Evapotranspiration (ET) } \\
\hline $\operatorname{RMSD}(\mathrm{mm})$ & 0.25 & 0.44 & 0.52 & 0.37 & 0.91 & 0.35 & 0.39 & 0.62 & 0.56 & 0.42 & 0.6 & 0.53 \\
\hline Bias (mm) & 0.08 & 0.21 & 0.12 & 0.18 & 0.8 & -0.002 & 0.28 & 0.55 & 0.33 & 0.13 & 0.33 & 0.39 \\
\hline MAPD (\%) & 21 & 11 & 14 & 34 & 42 & 8 & 40 & 19 & 12 & 12 & 15 & 17 \\
\hline \multicolumn{13}{|c|}{ Sensible Heat Flux (H) } \\
\hline RMSD (MJ) & 0.1 & 0.17 & 0.21 & 0.1 & 0.14 & 0.17 & 0.06 & 0.18 & 0.21 & 0.17 & 0.14 & 0.16 \\
\hline Bias (MJ) & -0.03 & -0.11 & -0.13 & 0.003 & -0.11 & -0.08 & -0.003 & -0.15 & -0.13 & -0.1 & -0.06 & -0.09 \\
\hline MAPD (\%) & 27 & 24 & 34 & 26 & 21 & 31 & 18 & 30 & 39 & 24 & 25 & 27 \\
\hline \multicolumn{13}{|c|}{ South Vineyard } \\
\hline \multicolumn{13}{|c|}{ Evapotranspiration (ET) } \\
\hline $\operatorname{RMSD}(\mathrm{mm})$ & 0.3 & 0.31 & 0.48 & 0.31 & 0.46 & 0.46 & 0.26 & 0.61 & 0.46 & 0.37 & 0.41 & 0.46 \\
\hline Bias (mm) & 0.04 & 0.11 & 0.19 & 0.02 & 0.1 & 0.33 & 0.14 & 0.5 & 0.28 & 0.12 & 0.15 & 0.31 \\
\hline MAPD (\%) & 22 & 9 & 12 & 21 & 12 & 11 & 18 & 18 & 10 & 12 & 13 & 14 \\
\hline \multicolumn{13}{|c|}{ Sensible Heat Flux (H) } \\
\hline RMSD (MJ) & 0.14 & 0.1 & 0.16 & 0.15 & 0.15 & 0.21 & 0.07 & 0.14 & 0.2 & 0.13 & 0.17 & 0.15 \\
\hline Bias (MJ) & 0.07 & 0.04 & -0.1 & 0.07 & 0.004 & -0.17 & 0.03 & -0.11 & -0.15 & 0.002 & -0.03 & -0.08 \\
\hline MAPD (\%) & 37 & 14 & 27 & 39 & 15 & 26 & 23 & 21 & 30 & 23 & 24 & 25 \\
\hline
\end{tabular}

BIAS=Average[Model-Observed]

RMSD $=$ Sqrt [Average $\left.\{\text { (Model-Observed })^{2}\right\}$ ]

MAPD $=100 *[$ Average $\{$ Absolute(Model-Observed) $\} /$ Average(Model) $]$

The likely reason that the period of greatest errors (in terms of MAPD) in TSEB output for north and south vineyards differ stems from the fact that generally larger $\mathrm{H}$ values were measured for the south vineyard during the growing season due to lower biomass/leaf area and less irrigation (see below in the discussion of Figure 6). It is evident from the yearly difference statistics in Table 1 that in general, the TSEB model performs slightly better in the south vineyard than in the north, which agrees with the results from Nieto et al. (this issue; a). Slightly better modelmeasurement agreement for the south vineyard may to some extent be due to greater variability in vine conditions in the north vineyard; this variability causes the $T_{R H}$ observations to be 
generally less representative of the flux measurement footprint of thermal imagery source area 257 (Knipper et al., this issue).

Figure 3 illustrates the effect of phenology-based $f_{G}$ (Eq. (1)) and temporal trend of LAI on the partitioning of LE between vine canopy or actively transpiring cover crop and the interrow senescent cover crop/bare soil. The ratio of daytime vine/cover crop LE (LEC or T) in mm to total LE or ET are shown for both north and south vineyards for each of the three study years. As one would expect, the temporal trend in $\mathrm{LEC}_{\mathrm{C}} / \mathrm{LE}$ or T/ET follows the temporal variations in
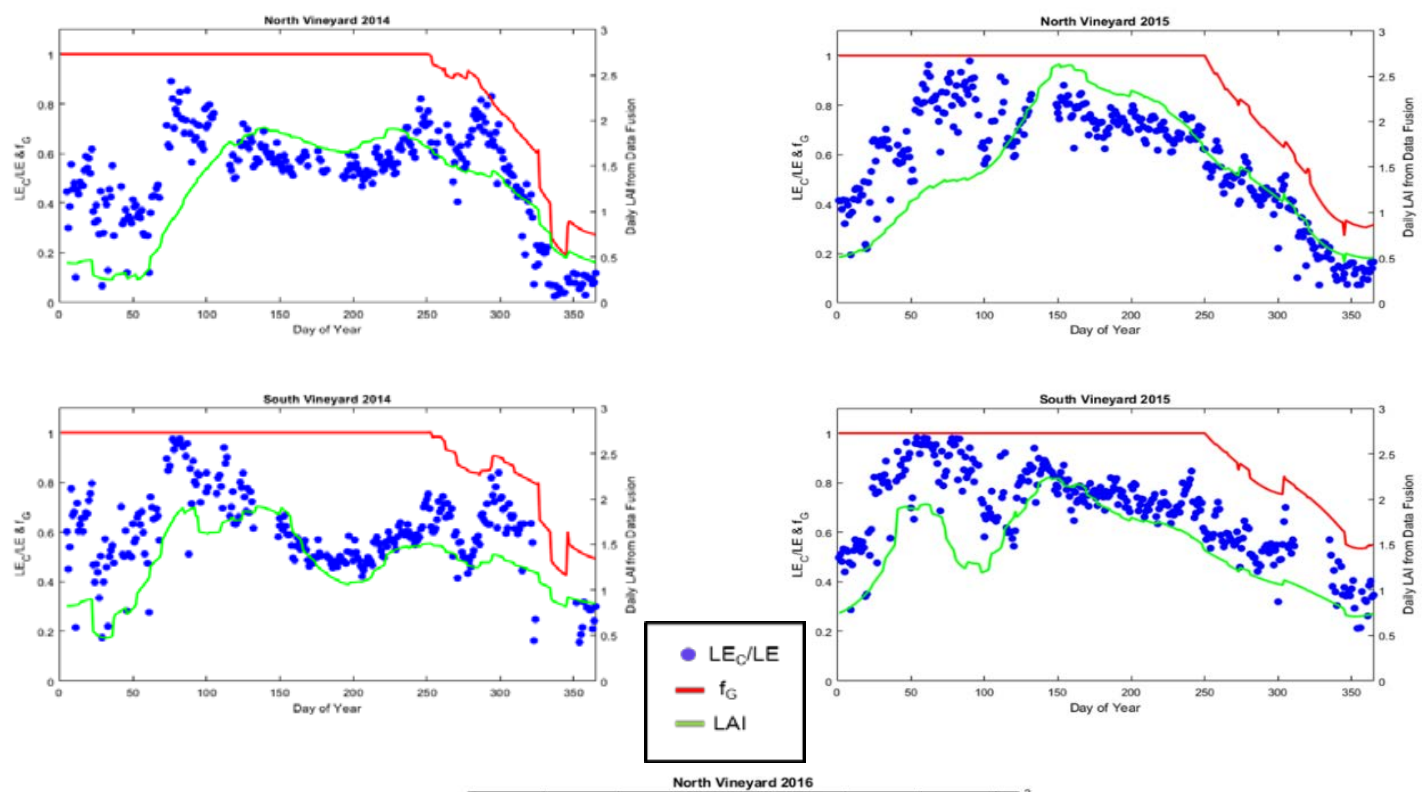

277

278

279

280

281
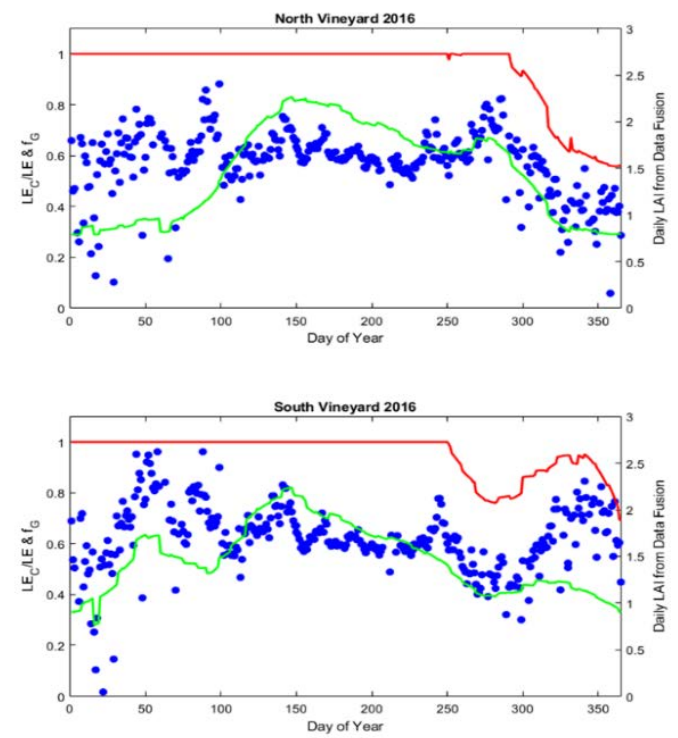

Figure 3. Daytime values of the ratio LEC/LE or T/ET estimated from TSEB for 2014-2016 using $f_{G}$ estimated from Eq. (1) and daily LAI from remote sensing retrievals. 
LAI. Early in the year, the cover crop is the primary contributor to T until it is mowed sometime in the middle of April ( DOY 100), usually soon after bud break. Then, LAI and T/ET increase as the vine canopy develops. By the end of June ( DOY 180), the vineyard phenology features transpiring vines and a fully senescent cover crop, and irrigation occurs every 2-3 days. Under these conditions one would expect T/ET near unity, but instead it decreases through the summer months as a result of the reduction of LAI through the veraison (July/early August, DOY 180220 ) and harvest (late August/early September (DOY 235-245) period. The downward trend of T/ET is further amplified after the start of senescence in mid-September (DOY DOY 260) due to the decreasing value of $f_{G}$.

Figure 4 shows T/ET computed with TSEB and with the EC-based method for 2014 and 2015. In 2014, the T/ET of TSEB is decreasing (concave) during the main months of the growing season (June-August) while the EC-based method computes an increasing (convex) T/ET. A decreasing T/ET as the interrow cover crop undergoes senescence and the only source of water is from drip irrigation along the vine rows, is contradictory to what would be expected and is supported by the EC-method. However, the TSEB input of LAI from the remote sensing retrieval also shows a concave relationship over the main growing season (see Fig. 3), which is supported to some extent by the periodic ground measurements (Sun et al., 2017; White et al., this issue). However, the actual temporal behavior of LAI may not be as significant or consistent as estimated by the remote sensing method.
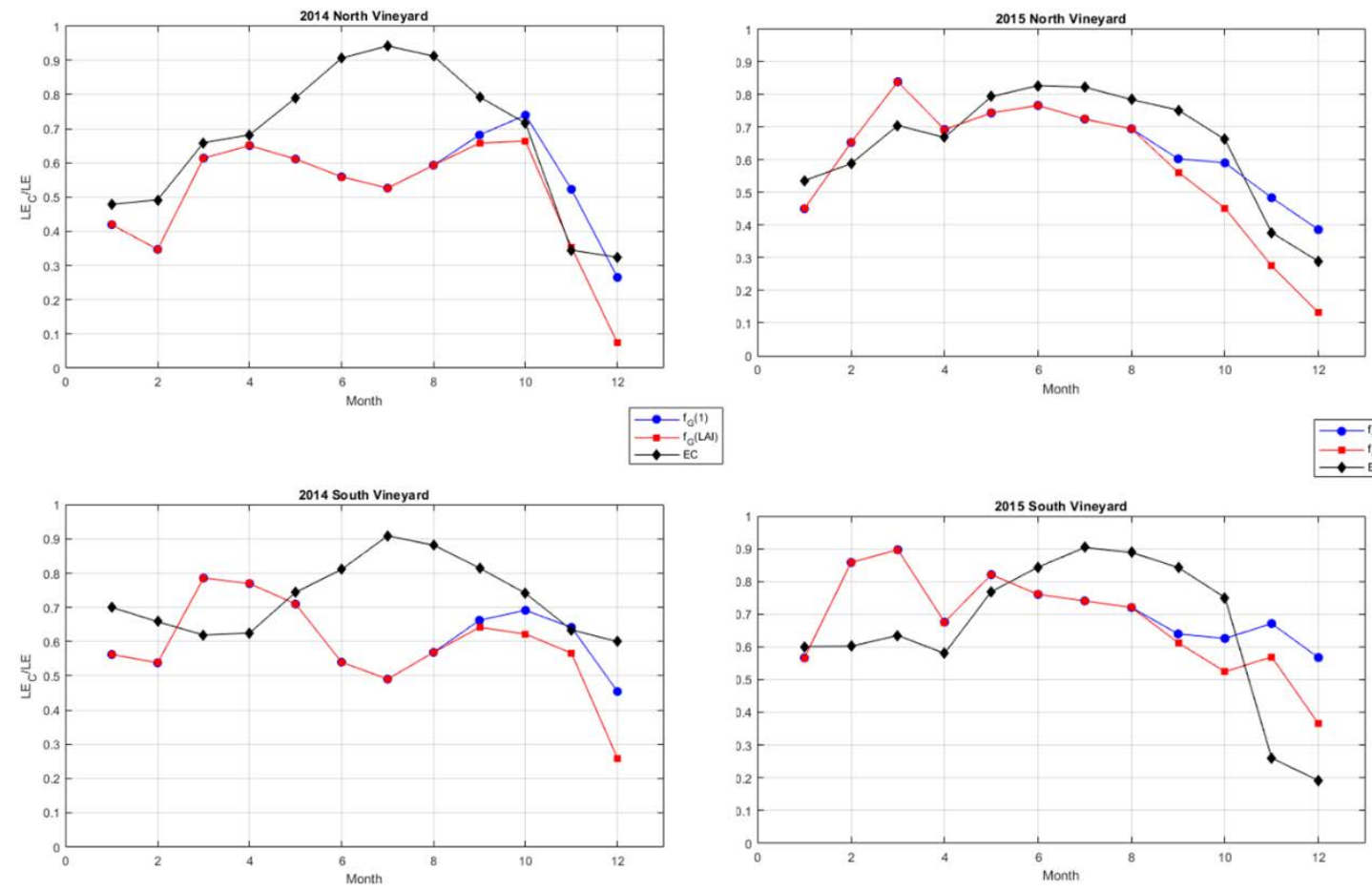

Figure 4. The monthly average values of LEC/LE or T/ET estimated from TSEB for 2014 and 2015 using $f_{G}$ estimated from Eq. (1), $f_{G}(\mathrm{LAI}), f_{G}=1, f_{G}(1)$ and estimated using the correlationbased flux partitioning method with the high frequency eddy covariance data. 
Better agreement between TSEB-derived T/ET (LEC/LE) monthly values and the EC method is observed for 2015 versus 2014, particularly for the north vineyard. Additionally, the agreement appears quite good during the senescent periods (October-February) and period up through bud break and flowering (March-May), particularly for 2015 and the north vineyard. Since much of the cover crop is senescent by end of June (DOY 180), one might expect T/ET to peak in July-August, which is what the estimates using the correlation-based flux partitioning method appear to show. This result needs to be tested with other independent measurements of vine transpiration and interrow cover crop and soil evaporation measurements. However, a major issue with using localized measurements of LST and LAI is the lack of representativeness in relation to the flux tower measurement source area footprint.

In 2015, there was a set of interrow flux observations collected using micro-Bowen ratio systems in the north vineyard described in Kustas et al. (this issue). The Bowen ratio, $H / L E$, is another way to express surface energy partitioning. There are only a handful of reliable measurements available during the four Intensive Observation Periods (IOPs). These were collected on DOY 113, 153, 192 and 224 which are late April (IOP 1) soon after bud break, early June (IOP2) near maximum LAI, mid-July (IOP 3) around the berry setting stage, and midAugust (IOP4) well into the veraison stage along with cane/vine maturation. Estimates of the T/ET ratio for these days were computed using the eddy covariance measurements of the total ET along with the micro-Bowen ratio estimates from the interrow comprising E from the bare soil areas and ET or E from the cover crop, which make up approximately $40 \%$ and $60 \%$ of the interrow, respectively. The estimated daily ratios of T/ET are compared with the TSEB estimates in Figure 5.

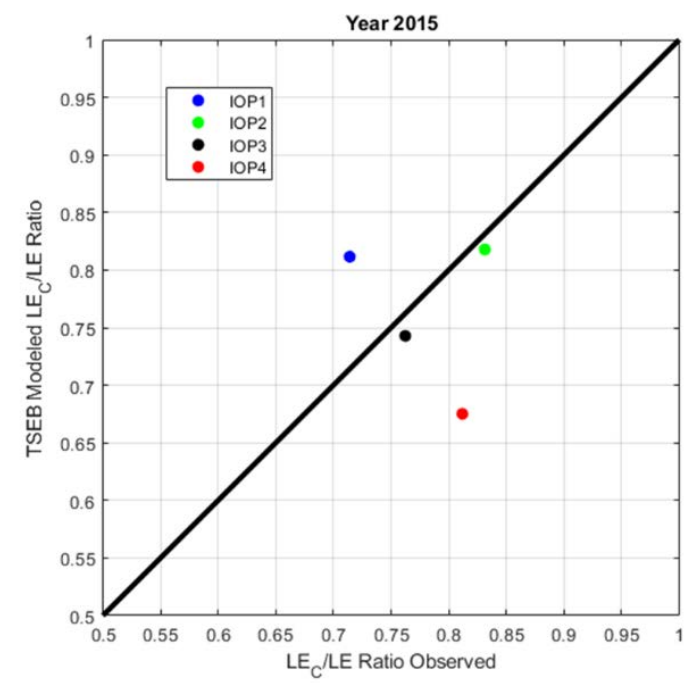

Figure 5. Comparison of TSEB model estimated daytime LEC/LE using $f_{G}$ estimated from Eq. (1) versus observed ratio for each of the four IOPs in 2015 (IOP 1=late April; IOP 2 = early June; IOP 3 = mid-July; IOP 4 = late August) using the tower ET and micro-Bowen ratio measurements of bare soil and cover crop interrow LE and LEC from the north vineyard (see Kustas et al., this issue). 
For IOP1, TSEB gives a higher T/ET than the micro-Bowen ratio estimate, while for IOP 2 and 3 the agreement in the T/ET partitioning is very good. However, for IOP 4 in August, the T/ET ratio from TSEB is significantly lower than estimated by the EC flux tower/micro-BR system, which is consistent with the monthly T/ET plots in Figure 4.

Figure 6 illustrates the difference in energy balance between the vine and interrow by way of the evaporative fraction $(\mathrm{EF}=\mathrm{LE} /(\mathrm{H}+\mathrm{LE}))$ of the vine/cover crop $\mathrm{EF}_{\mathrm{C}}=\mathrm{LEC}_{\mathrm{C}} /\left(\mathrm{H}_{\mathrm{C}}+\mathrm{LE}_{\mathrm{C}}\right)$ and the interrow bare soil/substrate $\mathrm{EFS}_{\mathrm{S}}=\mathrm{LES}_{\mathrm{S}} /\left(\mathrm{H}_{\mathrm{S}}+\mathrm{LEs}\right)$. Also plotted are the precipitation and
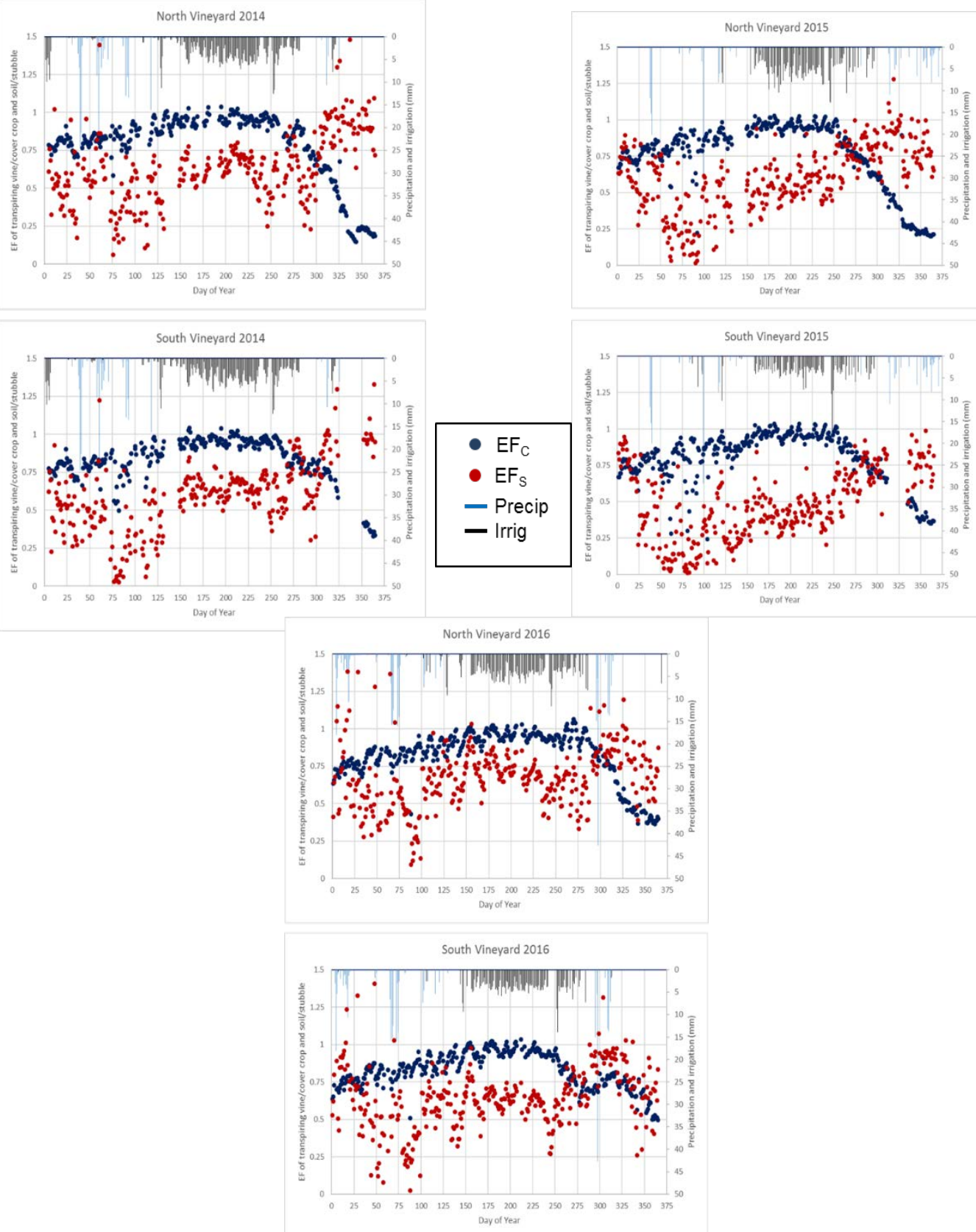

Figure 6. Evaporative fraction (EF) calculated using the TSEB model for the vine/cover crop $\left(E_{C}\right)$ and the interrow bare soil/senescent cover crop(EFs). 
irrigation events and amounts in $\mathrm{mm}$ and $\mathrm{mm} / \mathrm{vine}$, respectively. As expected, under these mostly well-watered conditions, $\mathrm{EF}_{\mathrm{C}}$ is near unity except during the period of leaf off through bud break, nominally the period DOY $<100$ and DOY $>275$, January-April and October-December, respectively. Main vine growth and berry development, concurrent with the majority of vineyard irrigation, occur from nominally DOY 125 through DOY 250, May-September.

Values of EFs tend to be lowest $\left(\mathrm{EFS}_{\mathrm{S}}<0.5\right)$ just prior to bud break ( DOY 100, early April) and highest (closer to 1) after leaf off, nominally DOY $>275$, early October. The low EFs values prior to bud break may be due to the re-emergence of the cover crop, while the higher values in $\mathrm{EFs}$ are likely due to irrigation after harvest and leaf off as well as winter precipitation during the senescence of both vines and cover. Depending on the year, the values of EFs during the main vine and berry growth and development period, roughly DOY 100-250 (April-early September), lie between 0.25 and 0.75 . However, one would expect for EFs values to generally be well below 0.5 during the main part of the growing season since $\mathrm{EFs}=0.5$ is equivalent to a Bowen ratio of order 1, or equal partitioning into $\mathrm{H}$ and LE. There are generally lower values of EFs for the south vineyard in 2015, which coincides with noticeably lower irrigation amounts; this trend is also evident to some extent in 2016 . Therefore, it may be that the frequent irrigations lead to higher than expected EFs values in the summer months; however, it also appears that in the TSEB formulation may not always properly partitioning $\mathrm{E}$ and $\mathrm{T}$, particularly late in the growing season.

\section{Summary and Conclusions}

Using hemispherical land surface temperature from tower upwelling longwave observations from 2014 through 2016, the TSEB model was run over all seasons with available data to compute surface energy fluxes with a focus on estimating daytime ET. Several of the original TSEB formulations of radiation and wind extinction through the vine canopy layer were modified based on the results of Nieto et al. (this issue). The resulting agreement between TSEBestimated daytime sensible $(\mathrm{H})$ and latent heat (LE) fluxes and flux tower observations indicated that for the north vineyard, the largest relative differences in LE (MAPD values) occurred in either the spring or during leaf-off and bud break periods for both $\mathrm{H}$ and LE, with the exception of 2016 where the largest differences in $\mathrm{H}$ were during the growing and senescent periods. For the south vineyard, the largest MAPD values were also from the leaf off and bud break periods, while for $\mathrm{H}$ it was also leaf off and bud break periods, except in 2016 which was during the growing season and senescent period. Since the south vineyard had less irrigated vine biomass, $\mathrm{H}$ was generally larger over the growing season, making relative errors smaller.

The TSEB model estimates the daytime source of LE or ET is primarily from the vine canopy during the growing season, although the model still estimates a significant contribution to 
LE from the bare soil/senescent cover crop. During periods of no or insignificant vine biomass, the transpiring interrow cover crop and bare soil mainly contributes to ET. Evaluation of the partitioning between soil and vegetation sources of LE shows that $\mathrm{LE}_{\mathrm{C}} / \mathrm{LE}$ or T/ET starts around 1 in early spring when the cover crop is rapidly growing and transpiring, decreases after cover crop mowing, increases again from bud break until peak LAI, gradually declines through harvest, and finally increases in late autumn as the cover crop rebounds. This partitioning between $\mathrm{E}$ and $\mathrm{T}$ is controlled in large part by the remotely sensed LAI estimates (see Fig. 3), which generally indicated a peak LAI in late May/early June followed by a gradual decline over the course of the growing season.

In 2014 and 2015, a near complete and continuous record of high frequency eddy covariance data allowed the estimation of monthly T/ET partitioning based on the correlation-based flux partitioning method. The comparison with monthly values from TSEB indicates that the 2015 growing season TSEB-derived T/ET agreed more closely with the correlation-based flux partitioning method than in 2014. In addition, selected days during the IOPs have T/ET estimates using micro-Bowen ratio measurements of E and ET components for the interrow cover crop and bare soil together with total ET from the flux towers. The agreement in the T/ET ratios was good for IOP 2 and 3, which were early June and mid-July but over and underestimated for IOPs 1 and 4 in late April and mid-August.

The partitioning ratios of $\mathrm{LE}_{\mathrm{C}} / \mathrm{LE}$ and $\mathrm{T} / \mathrm{ET}$ for the soil/substrate and vine canopy, calculated by TSEB, tend to be higher than the values from the correlation-based flux partitioning EC method during the leaf-off and bud burst periods but lower than the EC method values during the growing season through senescence. This temporal trend in T/ET partitioning estimated from TSEB is significantly affected by the temporal trend in LAI, which from the remote sensing method generally shows an increase in LAI in response to growth of the cover crop in the spring followed by a decline after cover crop mowing, and then an increase after bud burst in March until end of May/early June. This behavior is followed by a general decline over the growing season as the cover crop undergoes senescence and the vines are managed/pruned, and then after harvest the trend in T/ET continues to decrease as both the cover crop and vines are dormant during winter rains and cooler temperatures (Fig. 3).

The magnitude of the evaporative fraction of the soil/substrate $\left(\mathrm{EF}_{\mathrm{S}}\right)$ estimated by TSEB is generally scattered around $0.5( \pm 0.25)$ during the growing season; $\mathrm{EFs}=0.5$ indicates a Bowen ratio of 1 , or equal partitioning of the available energy between $\mathrm{H}$ and LE. This LEs component seems too large for the underlying non-irrigated senescent cover crop interrow, albeit approximately $40 \%$ of the interrow is composed of irrigated bare soil. The response of higher EFs values for the north vineyard, which tended to receive higher irrigation amounts, is plausible. However, one would still not expect EFs values to exceed 0.5. 
Clearly, more detailed measurements are needed to better determine whether the errors in partitioning are the result of biases or errors in the inputs to TSEB, principally in estimates of the leaf area and hemispherical land surface temperature. This study should include applying several methods for estimating the partitioning of ET into vine transpiration using sapflow gages and perhaps microlysimeters as well as more detailed below canopy measurements following the below canopy measurement design of Kool et al. (2016) for estimating $\mathrm{E}$ and when appropriate $\mathrm{T}$ contributions from the interrow.

Reliable estimates of vine transpiration relative to the total ET is valuable information for determining vine water use and stress, both of which influence grape yield and quality. This has led others to develop crop water stress indices using very high resolution aerial thermal imagery to define vine only stress and water potential for irrigation scheduling (Bellvert et al., 2016). With coarser resolution thermal imagery routinely available from satellites (Semmens et al., 2016; Knipper et al., this issue), reliable partitioning of ET into T and E, particularly during the vine growing season, could be used to define a stress index which could relate to the crop/vine water stress index and lead to estimating leaf/vine water potential for irrigation scheduling at the 496 field scale. 
2

3

\section{Acknowledgements}

519 Funding provided by E.\&J. Gallo Winery contributed towards the acquisition and processing of 520 the ground truth data collected during GRAPEX IOPs. In addition, we would like to thank the 521 staff of Viticulture, Chemistry and Enology Division of E.\&J. Gallo Winery for the assiatnce in 522 the collection and processing of field data during GRAPEX IOPs. Finally, this project would not 523 have been possible without the cooperation of Mr. Ernie Dosio of Pacific Agri Lands

524 Management, along with the Borden vineyard staff, for logistical support of GRAPEX field and 525 research activities. The senior author would like to acknowledge financial support for this 526 research from NASA Applied Sciences-Water Resources Program [Announcement number 527 NNH16ZDA001N-WATER]. Proposal No. 16-WATER16_2-0005, Request Number:

528 NNH17AE39I. USDA is an equal opportunity provider and employer.

On behalf of all authors, the corresponding author states that there is no conflict of interest. 


\section{References}

Alfieri J, Kustas W, Gao F, Prueger J, Nieto H, Hipps L (this issue) Influence of wind direction on the effective surface roughness of vineyards. Irrigation Science

Anderson MC, Norman JM, Kustas WP, Houborg JM, Starks PJ, Agam N (2008) thermal-based remote sensing technique for routine mapping of land-surface carbon, water and energy fluxes from field to regional scales. Remote Sens. Environ., 112:4227-4241.

Bellvert J, Zarco-Tejada P, Marsal J, Girona J, Gonzalez-Dugo V, Fereres E (2016) Vineyard irrigation scheduling based on airborne thermal imagery and water potential thresholds. Australian Journal of Grape and Wine Research 22(2):307\{315, DOI 10.1111/ajgw.12173\}

Brutsaert W (1999) Aspects of bulk atmospheric boundary layer similarity under free-convective conditions. Rev. Geophys. 37(4):439-451

Brutsaert W (2005) Hydrology. An Introduction. ISBN-13 978-0-521-82479-8, Cambridge University Press

Colaizzi PD, Evett SR, Howell TA, Li F, Kustas WP, Anderson MC (2012a) Radiation model for row crops: I. Geometric view factors and parameter optimization. Agron. J. 104:225-240.

Colaizzi PD, Agam N, Tolk JA, Evett SR, Howell TA, Gowda PH, O’Shaughnessy SA, Kustas WP, Anderson MC (2014) Two-source energy balance model to calculate E, T, and ET: Comparison of Priestley-Taylor and Penman-Monteith formulations and two time scaling methods. Trans. ASABE, 57(2):479-498.

Colaizzi PD, Kustas WP, Anderson MC, Agam N, Tolk JA, Evett SR, Howell TA, Gowda PH, O'Shaughnessy SA (2012b) Two-source energy balance model estimates of evapotranspiration using component and composite surface temperatures. Adv. Water Resour., 50:134-151.

Colaizzi PD, Agam N, Tolk JA, Evett SR, Howell TA, O’Shaughnessy SA, Gowda PH, Kustas WP, Anderson MC (2016c) Advances in a two-source energy balance model : Partitioning of evaporation and transpiration for cotton using component and composite surface temperatures. Trans. ASABE 59(1): 181-197. Doi 10.13031/trans.59.11215.

Colaizzi PD, Evett SR, Agam N, Schwartz RC, Kustas WP (2016a) Soil heat flux calculation for sunlit and shaded surfaces under row crops: 1. model development and sensitivity analysis. Agric. Forest Meteorol. 216:115-128.

Colaizz PD, Evett SR, Agam N, Schwartz RC, Kustas WP, Cosh, MH, McKee LG (2016b) Soil heat flux calculation for sunlit and shaded surfaces under row crops: 2. model test. Agric.Forest Meteorol. 216: 129-140. 
Gao F, Anderson MC, Kustas WP, Wang Y (2012) A simple method for retrieving Leaf Area Index from Landsat using MODIS LAI products as reference. J. Appl. Remote Sens. 6, DOI: 10.1117/.JRS.1116.063554.

Goudriaan J (1977) Crop micrometeorology: A simulation stud. Tech. rep., Center for Agricultural Publications and Documentation, Wageningen

Hillel D (1998) Environmental Soil Physics. Academic Press

Knipper KR, 621 Kustas WP, Anderson MC, Aleri JG, Prueger JH, Hain CR, Gao F, Yang Y, McKee LG, Nieto H, Hipps LE, Alsina MM, Sanchez L (this issue) Evapotranspiration estimates derived using thermal-based satellite remote sensing and data fusion for irrigation management in California vineyards. Irrigation Science

Kondo J, Ishida S (1997) Sensible heat flux from the earth's surface under natural convective conditions. J. Atmos. Sci. 54(4):498-509

Kool D, Agam N, Lazarovitch N, Heitman JL, Sauer TJ, Ben-Gal A (2014) A review of approaches for evapotranspiration partitioning. Agric. For. Meteorol. 184:56-70.

Kool D, Kustas WP, Ben-Gal A, Lazarovitch N, Heitman JL, Sauer TJ, Agam N (2016) Energy and evapotranspiration partitioning in a desert vineyard. Agric. For. Meteorol. 218-219: 277287.

Kustas WP, Norman JM (1999) Evaluation of soil and vegetation heat flux predictions using a simple two-source model with radiometric temperatures for partial canopy cover. Agric. For. Meteorol. 94:13-29.

Kustas W, Norman JM (2000) A two-source energy balance approach using directional radiometric temperature observations for sparse canopy covered surfaces. Agron. J. 92(5):847854.

Kustas WP, Nieto H, Morillas L, Anderson MC, Alfieri JG, Hipps LE, Villagarcía L, Domingo F, García M (2016) Revisiting the paper "using radiometric surface temperature for surface energy flux estimation in mediterranean drylands from a two-source perspective". Remote Sens. Environ. 184:645-653

Massman W (1987) A comparative study of some mathematical models of the mean wind structure and aerodynamic drag of plant canopies. Bound.-Layer Meteorol. 40(1):179-197

Massman W, Forthofer J, Finney M (2017) An improved canopy wind model for predicting wind adjustment factors and wildland fire behavior. Canadian J. Forest Res. 47(5):594-603

Nieto H, Kustas W, Gao F, Alfieri J, Torres A, Hipps L (this issue a) Impact of different withincanopy wind attenuation formulations on modelling evapotranspiration using TSEB. Irrigation Science 
Nieto H, Kustas WP, Torres-Rúa A, Alfieri JG, Gao F, Anderson MC, White WA, Song L, del Mar Alsina M, Prueger JH, McKee M, Elarab M, McKee LG (this issue b) Evaluation of TSEB turbulent fluxes using different methods for the retrieval of soil and canopy component temperatures from UAV thermal and multispectral imagery. Irrigation Science

Norman JM, Becker F (1995) Terminology in thermal infrared remote sensing of natural surfaces, Remote Sens. Rev., 12:159-173.

Norman JM, Kustas WP, Humes KS (1995) Source approach for estimating soil and vegetation energy fluxes in observations of directional radiometric surface temperature. Agric. Forest Meteorol. 77(3-4):263-293.

Parry CK, Nieto H, Guillevic P, Agam N, Kustas WP, Alfieri J, McKee L, McElrone AJ (this issue) An intercomparison of radiation partitioning models in vineyard row structured canopies. Irrigation Science

Priestley CHB, Taylor RJ (1972) On the assessment of surface heat flux and evaporation using large-scale parameters. Monthly Weather Review 100(2):81-92

Sauer TJ, Norman JM, Tanner CB, Wilson TB (1995) Measurement of heat and vapor transfer coefficients at the soil surface beneath a maize canopy using source plates. Agric. Forest Meteorol. 75(1-3):161 - 189.

Santanello Jr J, Friedl M (2003) Diurnal covariation in soil heat flux and net radiation. J. Applied Meteorol. 42(6):851-862.

Scanlon TM, Kustas WP (2010) Partitioning carbon dioxide and water vapor fluxes using correlation analysis. Agric. For. Meteorol. 150:89-99.

Scanlon TM, Kustas WP (2012) Partitioning evapotranspiration using an eddy covariance-based technique: Improved assessment of soil moisture and land-atmosphere exchange dynamics.

Vadose Zone J., 11, DOI: 10.2136/vzj2012.0025

Scanlon TM, Sahu P (2008) On the correlation structure of water vapor and carbon dioxide in the atmospheric surface layer: A basis for flux partitioning. Water Resour. Res. 44, W10418. URL: http: //onlinelibrary.wiley.com/doi/10.1029/2008WR006932/abstract, doi:10.1029/2008WR006932.

Semmens KA, Anderson MC, Kustas WP, Gao F, Alfieri JG, McKee L, Prueger JH, Hain CR, Cammalleri C, Yang Y, Xia T, Sanchez L, Alsina MM, Vélez M (2016) Monitoring daily evapotranspiration over two California vineyards using Landsat 8 in a multi-sensor data fusion approach. Remote Sens. Environ. 185:155 - 170, DOI 10.1016/j.rse.2015.10.025

Sun L, Gao F, Anderson MC, Kustas WP, Alsina M, Sanchez L, Sams B, McKee LG, Dulaney WP, White A, Alfieri JG, Prueger JH, Melton F, Post K (2017) Daily mapping of 30 m LAI, 
4666 NDVI for grape yield prediction in California vineyard. Rem. Sens., 9, 317; 18 pp.

667 doi: $10.3390 /$ rs 9040317

668

8669 White AW, Alsina M, Nieto H, McKee L., Gao F, Kustas WP (this issue) Indirect measurement

670 of leaf area index in California vineyards: Utility for validation of remote sensing-based 671 retrievals. Irrigation Science. 


\section{Appendix A TSEB model}

The basic equation of the energy balance at the surface can be expressed following Eq. A1.

$$
\begin{gathered}
R_{n} \approx H+L E+G \\
R_{n, S} \approx H_{S}+L E_{S}+G \\
R_{n, C} \approx H_{C}+L E_{C}
\end{gathered}
$$

with $R_{n}$ being the net radiation, $H$ the sensible heat flux, $L E$ the latent heat flux or evapotranspiration, and $G$ the soil heat flux. " $C$ " and " $S$ " subscripts refer to canopy and soil layers respectively. The symbol " $\approx$ " appears since there are additional components of the energy balance that are usually neglected, such as heat advection, storage of energy in the canopy layer or energy for the fixation of $\mathrm{CO}_{2}$ (Hillel, 1998)

The key in TSEB models is the partition of sensible heat flux into the canopy and soil layers, which depends on the soil and canopy temperatures ( $T_{S}$ and $T_{C}$ respectively). If we assume that there is an interaction between the fluxes of canopy and soil, due to an expected heating of the in-canopy air by heat transport coming from the soil, the resistances network in TSEB is considered in series. In that case $H$ can be estimated as in Eq. A2 (Norman et al, 1995, Eqs. A1A3)

$$
\begin{array}{cc}
H=H_{C}+H_{S}= & \rho_{a i r} C_{p} \frac{T_{A C}-T_{A}}{R_{a}} \\
= & \rho_{\text {air }} C_{p}\left[\frac{T_{C}-T_{A C}}{R_{x}}+\frac{T_{S}-T_{A C}}{R_{S}}\right]
\end{array}
$$

688 where $\rho_{\text {air }}$ is the density of air $\left(\mathrm{kg} \mathrm{m}^{-3}\right), C_{p}$ is the heat capacity of air at constant pressure $\left(\mathrm{J} \mathrm{kg}^{-1}\right.$ $\left.689 \mathrm{~K}^{-1}\right), T_{A C}$ is the air temperature at the canopy interface, equivalent to the aerodynamic 690 temperature $T_{0}$, computed as follows (Norman et al., 1995, Eq. 4):

$$
T_{A C}=\frac{\frac{T_{A}}{R_{a}}+\frac{T_{C}}{R_{\chi}}+\frac{T_{S}}{R_{S}}}{\frac{1}{R_{a}}+\frac{1}{R_{x}}+\frac{1}{R_{S}}} \quad \text { (A3). }
$$

Here, $R_{a}$ is the aerodynamic resistance to heat transport $\left(\mathrm{s} \mathrm{m}^{-1}\right), R_{s}$ is the resistance to heat flow in the boundary layer immediately above the soil surface $\left(\mathrm{s} \mathrm{m}^{-1}\right)$, and $R_{x}$ is the boundary layer resistance of the canopy of leaves $\left(\mathrm{s} \mathrm{m}^{-1}\right)$. The mathematical expressions of these resistances are detailed in Norman et al. (1995) and Kustas and Norman (2000), discussed in Kustas et al. (2016), and shown below:

$$
\begin{gathered}
R_{a}=\frac{\ln \left(\frac{z_{T}-d_{0}}{z_{0 H}}\right)-\Psi_{h}\left(\frac{z_{T}-d_{0}}{L}\right)+\Psi_{h}\left(\frac{z_{0 H}}{L}\right)}{\kappa^{\prime} u_{*}} \\
R_{S}=\frac{1}{c\left(T_{S}-T_{A}\right)^{1 / 3}+b u_{s}} \\
R_{x}=\frac{C^{\prime}}{L A I}\left(\frac{l_{w}}{U_{d_{0}+z_{0 M}}}\right)^{1 / 2}
\end{gathered}
$$

698 where $u_{*}$ is the friction velocity $\left(\mathrm{m} \mathrm{s}^{-1}\right)$ computed as:

$$
u_{*}=\frac{\kappa^{\prime} u}{\left[\ln \left(\frac{z_{u}-d_{0}}{z_{0 M}}\right)-\Psi_{m}\left(\frac{z_{u}-d_{0}}{L}\right)+\Psi_{m}\left(\frac{z_{0 M}}{L}\right)\right]}
$$


In Eq. A5, $z_{u}$ and $z_{T}$ are the measurement heights for wind speed $u\left(\mathrm{~m} \mathrm{~s}^{-1}\right)$ and air temperature $T_{A}(\mathrm{~K})$, respectively. $d_{0}$ is the zero-plane displacement height, $z_{0 M}$ and $z_{0 H}$ are the roughness length for momentum and heat transport respectively (all those magnitudes expressed in $\mathrm{m}$ ), with $z_{0 H}=z_{0 M} \exp \left(-k B^{-1}\right)$. In the series version of TSEB $z_{0 H}$ is assumed to be equal to $z_{0 M}$ since the term $R_{x}$ already accounts for the different efficiency between heat and momentum transport (Norman et al., 1995), and therefore $k B^{-1}=0$. The value of $\kappa^{\prime}=0.4$ is the von Karman's constant. The $\Psi_{m}$ and $\Psi_{h}$ terms in Eqs. A4 and A5 are the adiabatic correction factors for momentum and heat, respectively, whose formulations are described in Brutsaert $(1999,2005)$ and are functions of the atmospheric stability. The stability is expressed using the MoninObukhov length $L(\mathrm{~m})$, which has the following form:

$$
L=\frac{-u_{*}^{3} \rho_{\text {air }}}{k g\left[H /\left(T_{A} C_{p}\right)+0.61 E\right]}
$$

where $H$ is the bulk sensible heat flux $\left(\mathrm{W} \mathrm{m}^{-2}\right), E$ is the rate of surface evaporation $\left(\mathrm{kg} \mathrm{s}^{-1}\right)$, and $g$ the acceleration of gravity $\left(\mathrm{m} \mathrm{s}^{-2}\right)$.

The coefficients $b$ and $c$ in Eq. A4 depend on turbulent length scale in the canopy, soilsurface roughness and turbulence intensity in the canopy, which are discussed in Sauer et al (1995), Kondo and Ishida(1997) and Kustas et al.(2016). $C^{\prime}$ is assumed to be $90 \mathrm{~s}^{1 / 2} \mathrm{~m}^{-1}$ and $l_{w}$ is the average leaf width (m).

Wind speed at the heat source-sink $\left(z_{0 M}+d_{0}\right)$ and near the soil surface was originally estimated in TSEB using the Goudriaan (1977) wind attenuation model:

$$
\begin{array}{cc}
U(z)= & U_{C} \exp \left[-a_{G}\left(1-z / h_{c}\right)\right] \\
a_{G}= & 0.28 L A I^{2 / 3} h_{c}^{1 / 3} l_{w}{ }^{-1 / 3}
\end{array}
$$

For the vineyards, Nieto et al. (this issue) utilized a new wind profile formulation developed by Massman et al. (2017). This canopy wind profile model is a more physically-based method for calculating wind speed attenuation for the canopies of vertically non-uniform foliage distribution and leaf area that often exist in orchards and vineyards.

When only a single observation of $T_{\text {rad }}$ is available (i.e. measurement at a single angle), partitioning of $T_{\text {rad }}$ into canopy and soil components $\left(T_{C}\right.$ and $\left.T_{S}\right)$ is required to estimate component sensible heat fluxes via Eq. A2. The approach developed for TSEB (Norman et al., $1995)$ starts with an initial estimate of plant transpiration $\left(\lambda E_{C}\right)$, as defined by the Priestley and Taylor(1972) relationship, applied to the canopy divergence of net radiation $\left(R_{n, C}\right)$

$$
L E_{C}=\alpha_{P T} f_{g} \frac{\Delta}{\Delta+\gamma} R_{n, C}
$$

730 Here, $\alpha_{P T}$ is the Priestley-Taylor coefficient, initially set to $1.26, f_{g}$ is the fraction of vegetation 731 that is green and hence capable of transpiring, $\Delta$ is the slope of the saturation vapor pressure 732 versus temperature curve, and $\gamma$ is the psychrometric constant. This method allows the canopy 733 sensible heat flux to be calculated using the energy-balance at the canopy layer $\left(H_{c}=R_{n, C}-\right.$ 
$\left.L E_{C}\right)$ and hence an estimate of $T_{C}$ to be obtained by rewriting Eq. A8 to have the following form 735 (Norman et al, 1995):

$$
T_{C i}=T_{a}+\frac{R_{n, C} R_{a}}{\rho C_{p}}\left[1-\alpha_{P T} f_{G} \frac{\Delta}{\Delta+\gamma}\right]
$$

738

where $T_{C i}$ is the initial estimate of canopy temperature. Alternatively, $T_{C i}$ can be derived with the linearization approximation to the series resistance approach described in Appendix A of Norman et al. (1995), specifically Eqs. A7, A11 and A12. Then, $T_{S}$ is the derived from the following using $T_{r a d}, T_{C}$, and an estimate of $f_{c}(\theta)$, the fraction of vegetation observed by the sensor view zenith angle $\theta$ :

$$
T_{\text {rad }}^{4}(\theta)=f_{c}(\theta) T_{C}^{4}+\left[1-f_{c}(\theta)\right] T_{S}^{4}
$$

The value of $f_{c}(\theta)$ is typically estimated as an exponential function of the leaf area index (LAI), which includes a clumping factor or index $\Omega$ for canopies where the LAI is concentrated for sparsely distributed plants or for organized canopies such as row crops (Kustas and Norman, 1999; Anderson et al., 2005), and has the following form:

$$
f_{C}(\theta)=1-\exp \left(\frac{-0.5 \Omega L A I}{\cos \theta}\right)
$$

However due, to the unique vertical canopy structure and wide row width relative to canopy height of vineyards, a new method to derive $\Omega$ had to be developed that was both based on the geometric model of Colaizzi et al.(2012a) and simple enough to be incorporated into TSEB. Parry et al. (this issue) compared radiation extinction models of different complexities and found the simplified geometric model developed by Nieto et al (this issue) was a robust modified radiation scheme. The resulting effective $L A I, L A I_{\text {eff }}=\Omega L A I$, was then used as input in the Campbell and Norman (1998) canopy radiative transfer model to estimate soil and canopy net radiation, $R_{n, S}$ and $R_{n, C}$, respectively (see also Kustas and Norman (2000) for details).

The final energy balance component of soil heat flux, $G$, is typically estimated by TSEB as a fraction of the net radiation at the soil surface, $R_{n, S}$. However, over the daytime period, the assumption of a constant ratio between $G$ and $R_{n, S}$ is unreliable (Santanello and Friedl, 2003; Colaizzi et al., 2016a, b). Based on observations between the measured soil heat flux and the estimated $R_{n, S}$ in Nieto et al (this issue; a), a modified formulation estimating $G$ as a function of $R_{n, S}$ was adopted that accounts for the temporal behavior of the $G / R_{n, S}$ ratio over the daytime period using a double asymmetric sigmoid function; this estimate was a significantly better fit to the observations than the sinusoidal function proposed by Santanello and Friedl (2003). 
With $R_{n, S}$ and $G$ estimated and $H_{S}$ computed via $T_{S}$ estimated from Eqs. A9-A11, iteratively 770 solving for Eqs. A2-A7 results in $L E_{s}$ solved as a residual via Eq. A1 for the soil layer, namely $7771 L E_{S}=R_{n, S}-G-H_{S}$.

772 In some cases, the initial $T_{C}$ implied by the Priestley-Taylor approximation (Eq. A9) results in 773 deriving a relatively high value of $T_{S}$ for a given observed $T_{\text {rad }}$ and $f_{c}(\theta)$ condition. This high $T_{S}$ 774 can cause a significant overestimate in $H_{S}$ and therefore produce unrealistic estimates of $L E S$ 775 (i.e., negative values during daytime; $L E_{S}<0$ ) solved by residual. In this case, the $\alpha_{P T}$ coefficient 5776 is iteratively reduced at 0.1 intervals from its initial value $\sim 1.3$, effectively assuming the canopy 6777 is stressed and transpiring at sub-potential levels until $L E_{s} \geq 0$. 